\title{
Erratum zu: Das „Christian Doppler Labor für Sediment- forschung und -management": Anwendungsorientierte Grundlagenforschung und Herausforderungen für eine nachhaltige Wasserkraft und Schifffahrt
}

Christoph Hauer $\cdot$ Beatrice Wagner $\cdot$ Johann Aigner $\cdot$ Patrick Holzapfel $\cdot$ Peter Flödl $\cdot$ Marcel Liedermann ·
Michael Tritthart $\cdot$ Christine Sindelar $\cdot$ Mario Klösch $\cdot$ Marlene Haimann $\cdot$ Helmut Habersack

Online publiziert: 28. Februar 2019

(c) Österreichischer Wasser- und Abfallwirtschaftsverband (ÖWAV) and Springer-Verlag GmbH Austria, ein Teil von Springer Nature 2019

\section{Erratum zu:}

Österr Wasser- und Abfallw 2018

https://doi.org/10.1007/s00506-019-

0559-z

Durch einen Produktionsfehler wurde leider Abb. 7 mit einer inkorrekten Achsenbeschriftung publiziert. Der Originalartikel wurde korrigiert und die korrekte Abbildung ist hier abgebildet.-

PD DI Dr. C. Hauer $(\bowtie) \cdot$

DI B. Wagner · DI J. Aigner

DI P. Holzapfel · DI P. Flödl, BSc. ·

DI Dr. M. Liedermann .

PD DI Dr. M. Tritthart .

DI M. Klösch · DI M. Haimann .

Univ.-Prof. DI Dr. H. Habersack

Department für

Wasser-Atmosphäre-Umwelt,

Christian Doppler Labor

für Sedimentforschung

und -management, Institut

für Wasserbau, Hydraulik

und Fließgewässerforschung,

Universität für Bodenkultur Wien,

Muthgasse 107, 1190 Wien, Österreich

christoph.hauer@boku.ac.at

DI Mag. Dr. C. Sindelar

Department für

Wasser-Atmosphäre-Umwelt,

Christian Doppler Labor

für Sedimentforschung

und -management, Institut

für Wasserbau, Hydraulik

und Fließgewässerforschung,

Universität für Bodenkultur Wien,

Die Online-Version des Originalartikels

Muthgasse 18, 1190 Wien, Österreich 


\section{Erratum}
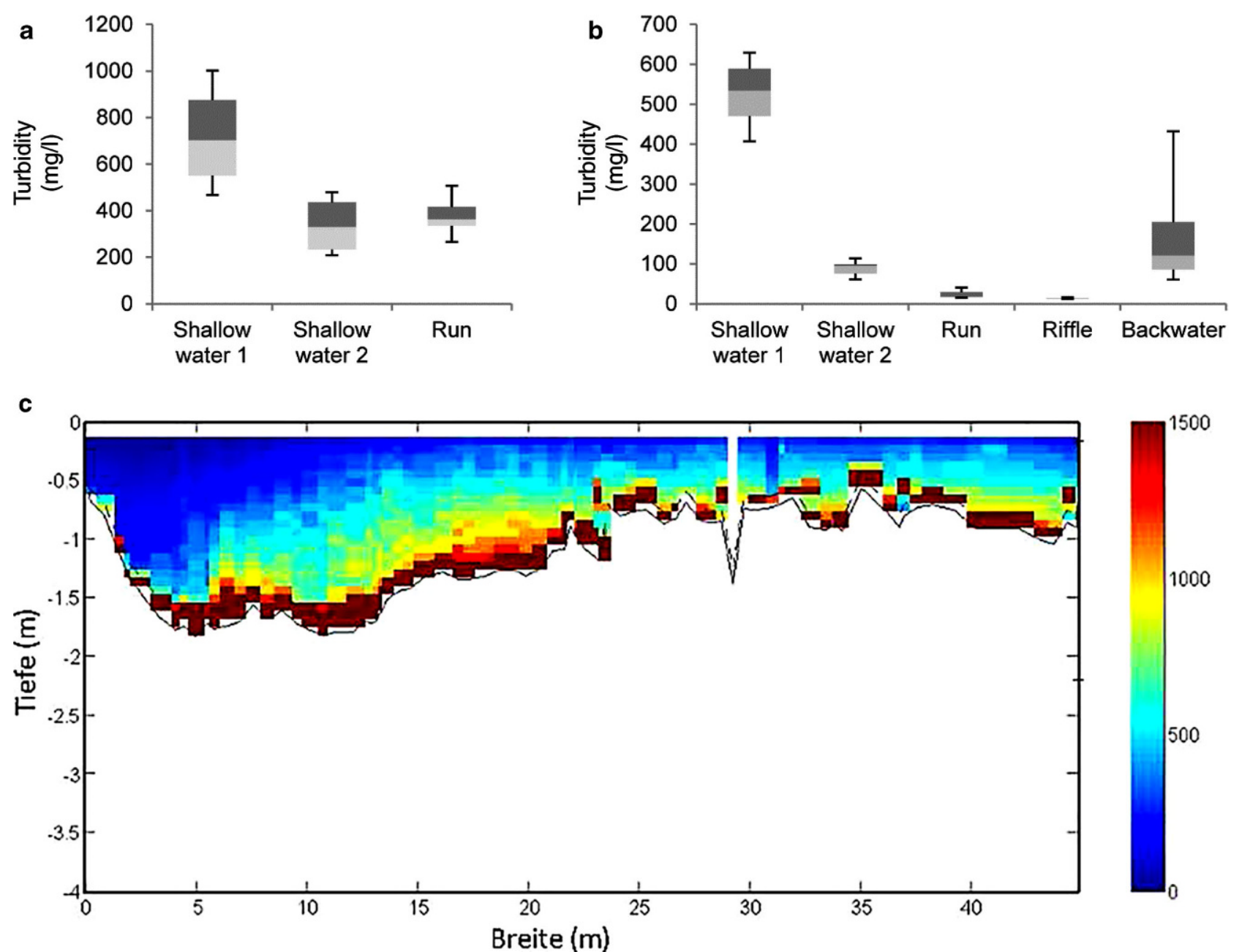

Abb. 7 Habitatbezogene Variation der Trübung an verschiedenen Standorten und Messzeitpunkten während der kontrollierten Absenkung des Gepatsch-Speichers 